However, this half, as stated before, may differ widely in density from the first. If the diamond is a poor one and scratches or merely rubs the glass surface, the resulting band, if present at all, is always of width $2 O D$.

Others may also have observed the one-sidedness of this phenomenon when using a new glazier's diamond.

Cavendish Laboratory,

Cambridge, July 20.

\section{Atmospheric Electricity}

In NatuRe of Mar. 5 (Suppt., p. 6), Dr. Chree gave an excellent review of my book "Die elektrische Leitfähigkeit der Atmosphäre und ihre Ursachen", (Vieweg und Sohn, Braunschweig, 1926), which will appear in English within this year. I am much pleased to see that Dr. Chree, who is an authority of world-wide reputation in atmospheric electricity, finds my book valuable and not inferior to the recent French monographs on atmospheric electricity by the late B. Chauveau and by Dr. Mathias and his coworkers.

Nevertheless, I should like to make a few comments upon Dr. Chree's review in order to remove one or two misunderstandings. Dr. Chree seems to object to my use of the term "Kennelly-Heaviside-layer" instead of " Heaviside-layer." I thought I was justified in using the first expression because in the American journal Science (1925) it was stated that Kennelly was the first to postulate the existence of the conductive layer in the upper atmosphere, and not Heaviside. If in this I am wrong, I will gladly alter this in the English edition of my book.

At the end of his review Dr. Chree says: "Dr. Hess does not, however, seem to notice that if the somewhat serious defect in the Ebert apparatus, which he accepts as proved by Prof. Swann, really exists, then much of the information which appears in the present book and elsewhere respecting negative ions must require correction." To this I must add that in choosing the numerical data on ionic numbers for my book I tried to select only those taken in places where the apparatus was well screened from the electric field of the atmosphere. Observations taken under these conditions are fortunately more numerous than those unscreened in the open air, and therefore I believe that the data given in my book require no correction whatever. From my own experience I should think that the effect of the earth's field disclosed by Swann was overestimated in some cases, and that the distribution of ions, as found in electrically well-screened places (under the leaves of trees, in open windows, verandahs, etc.), is not very different from that in the open air. $\quad$ V. F. Hess.

University of Graz, Austria.

WITH regard to the 'sonducting layer,' my objection was to associating it with the name of either Heaviside or Kennelly. It would probably be best, as in the case of the "penetrating radiation,' to attach no personal name, but if a name is to be attached, the claims of Balfour Stewart, as I have already explained in the columns of NATURE, seem to me to come first.

With regard to results from the Ebert apparatus, I noticed no explicit statement in the text that only those stations had been included where the apparatus was specially sheltered, and in at least one or two of the cases mentioned I had reason to believe that the contrary was the case. I am personally inclined to share the doubt now expressed by Prof. Hess whether
Prof. Swann's unfavourable conclusions are in actual practice fully justified. Some experiments, in fact, made at Kew Observatory by Mr. E. H. Nichols ("Terrestrial Magnetism and Atmospheric Electricity," 1916, p. 87) did not confirm Prof. Swann's conclusions. But there seems no reference to these in Prof. Hess's book, and I had supposed him to accept Prof. Swann's conclusions without reserve. My own view is that an independent investigation into the conditions under which the use of the Ebert apparatus is wholly satisfactory would be useful. I am glad to hear that we may expect an English version of Prof: Hess's valuable book.

C. Chree.

\section{The Depth to which Whales Descend.}

WHEN a whale is attacked, it usually attempts to escape by 'sounding' or going vertically down; the rope it takes out on these occasions is a good measure of the depth it descends to, and the attacking boat, owing to the strain on the line, an indicator of its position under water.

The Right-whales appear to descend to greater depths than the Fin-whales, and on this account to be more easily captured. When the Greenland whale is attacked, it usually leaves the surface and descends immediately; it takes out rope very quickly and soon reaches a great depth. After a time it reappears near where it went down in an exhausted condition and is easily captured. Large ones appear to descend to a depth of 700-800 fathoms and remain under water nearly an hour. Sometimes the Greenland whale dies at a depth of 800 fathoms, and sometimes, as related by Scoresby, if the depth of the water is not sufficiently great, it strikes the bottom while descending and kills itself in this way ; in both cases it has to be hauled up dead.

It is only when it is attacked in very deep water with the hand or simple gun harpoon, as in former days, that the Greenland whale descends to a great depth and that the boats engaging in its capture require to carry a very long line ; in water of moderate depth a much shorter one suffices. This fact is surely in itself a sufficient answer to those who, on purely theoretical grounds, deny that whales can descend to great depths.

The blubber of whales appears to be related in some way to the depths to which they descend. In the Greenland whale, for example, it is very much thicker than in its congener the narwhal; perhaps its great thickness enables it to withstand the pressure at great depths ?

R. W. Grax.

\section{Ophion luteus.}

THE shrill sound of this fly is here a sure nocturnal herald of the Dog Days. Nearly six years ago I described in NatURE (Nov. 10 and Dec. I, 1921) how some members of my household had been stung by the fly; but it was not until last night that I was favoured by its attention. The weather being very sultry, I was sleeping under a single sheet when I was awakened by a sharp stab in my thigh. Clapping a hand on the place, I missed the intruder; but immediately after was stung on the left arm and this time caught Ophion luteus.

The incident would not be worth recording were it not that it puzzles one to understand what can be the motive in this fly, when not molested, in thrust. ing its ovipositor into a human being. It would be interesting to hear whether other persons have received similar attention from this or any other species of Ichneumonidæ. HERBERT MAXWFit.

Monreith, Whauphill,

Wigtownshire, Aug. 7.

No. 3016, VoL. 120] 